\title{
Facilidades de adesão familiar no tratamento da dependência química: percepção dos familiares*
}

\section{Ana Carolina Belmonte Assalin \\ iD https://orcid.org/0000-0002-7363-8924 \\ Sonia Regina Zerbetto ${ }^{2}$ \\ (iD) https://orcid.org/0000-0002-2522-1948 \\ Bianca Oliveira Ruiz ${ }^{3}$ \\ (iD) https://orcid.org/0000-0002-4464-8939 \\ Priscila Souza Cugler ${ }^{4}$ \\ (iD) https://orcid.org/0000-0001-8807-970X \\ Sarah Salvador Pereira ${ }^{2,5}$ \\ (iD) https://orcid.org/0000-0002-1151-6374}

Apoio financeiro da Fundação de Amparo à Pesquisa do Estado de São Paulo (FAPESP), Brasil, processo no 15/11013-1.

${ }^{1}$ Irmandade da Santa Casa de Misericórdia de São Carlos, Unidade de Emergência, São Carlos, SP, Brasil.

${ }^{2}$ Universidade Federal de São Carlos, Departamento de Enfermagem, São Carlos, SP, Brasil.

${ }^{3}$ Escola Técnica Estadual, Escola Técnica Estadual Paulino Botelho, São Carlos, SP, Brasil.

${ }^{4}$ Secretaria Municipal de Saúde, Centro de Atenção Psicossocial Álcool e Drogas, São Carlos, SP, Brasil.

${ }^{5}$ Bolsista da Coordenação de Aperfeiçoamento de Pessoal de Nível Superior (CAPES), Brasil.
Objetivo: analisar a percepção do membro familiar sobre as facilidades de adesão da família ao tratamento do dependente químico em acompanhamento no Centro de Atenção Psicossocial - álcool e drogas. Método: estudo qualitativo, realizado de abril a setembro de 2016, com 10 familiares de usuários de drogas, participantes de grupos de família. Realizou-se entrevista semiestruturada e os dados foram analisados pela técnica de análise de conteúdo temática. Resultados: as famílias reconheceram que criar alianças terapêuticas, ter esperança na recuperação de seu parente e valorizar seus papéis participativos no tratamento familiar facilitam a adesão terapêutica. Conclusão: o estudo contribui para a reflexão dos profissionais de saúde quanto às possíveis áreas estratégicas para o cuidado às famílias, de modo a ajudá-las na adesão terapêutica.

Descritores: Cooperação e Adesão ao Tratamento; Família; Relações Familiares; Transtornos Relacionados ao Uso de Substâncias; Saúde Mental.

\section{Como citar este artigo}

Assalin ACB, Zerbetto SR, Ruiz BO, Cugler PS, Pereira SS. Facilities of family adherence in treatment of chemical dependence: families' perception. SMAD, Rev Eletrônica Saúde Mental Álcool Drog. 2021 jan.- mar.;17(1):17-25. doi: https://dx.doi.org/10.11606/issn.1806-6976.smad.2021.150251 


\title{
Facilities for family adherence to chemical dependency treatment: family members' perception
}

\begin{abstract}
Objective: to analyze family members' perception of the facilities of family adherence to the treatment of their chemically-dependent relative being cared for at the Psychosocial Care Center alcohol and drugs. Method: qualitative study, conducted from April to September 2016, including 10 family members of drug users participating in family groups. A semi-structured interview was conducted and data were analyzed using the thematic content analysis technique. Results: families recognized that creating therapeutic alliances, hoping for their relatives' recovery and valuing their participatory roles in family treatment facilitate therapeutic adherence. Conclusion: the study contributes to health professionals' reflection regarding the possible strategic areas to care for families in order to help them with therapeutic adherence.
\end{abstract}

Descriptors: Treatment Adherence and Compliance; Family; Family Relations; Substance-Related Disorders; Mental Health.

\section{Facilidade de adhesión familiar en el tratamiento de la dependencia química: percepción de los familiares}

\begin{abstract}
Objetivo: analizar una percepción del membro familiar sobre las facilidades de adhésion de la familia, en nel tratamiento del dependiente químico en el Centro de Atención Psicosocial de alcohol y drogas. Método: estudio cualitativo, realizado de abril a septiembre de 2016, con 10 familiares de usuarios de drogas, participantes de grupos de familia. Se realizó una entrevista semiestructurada y los datos fueron analizados por la técnica de análisis de contenido temático. Resultados: las familias reconocieron que crear alianzas terapéuticas, tener esperanza en la recuperación de su pariente y valorar sus papeles participativos en el tratamiento familiar facilitan la adhesión terapéutica. Conclusión: el estudio contribuye a la reflexión de los profesionales de la salud en cuanto a las posibles áreas estratégicas para el cuidado a las familias, para ayudarlas en la adhesión terapéutica.
\end{abstract}

Descriptores: Cumplimiento y Adherencia al Tratamiento; Familia; Relaciones Familiares; Trastornos Relacionados con Sustancias; Salud Mental. 


\section{Introdução}

A família tem papel importante no processo de recuperação e reabilitação de seu membro dependente de substâncias psicoativas (SPAs), requerendo dela a sua adesão ao tratamento.

Apesar de a dependência química promover desequilíbrio intrafamiliar(1-2), a família pode se reorganizar e garantir o desenvolvimento de seus membros por meio do cuidado, afeto e da comunicação assertiva. Tal fato colabora para a adesão ao tratamento de seu parente ${ }^{(3-4)}$, e para a prevenção e resolução dos problemas relacionados ao consumo de substâncias psicoativas por parte de um ou mais de seus membros ${ }^{(4)}$.

Adesão e aderência (adherence) são definidas como grau de comprometimento do usuário em participar, colaborar, bem como seguir os cuidados ou recomendações terapêuticas propostas pelos profissionais de saúde, porém, reconhecendo-se a vontade e a autonomia dele ${ }^{(5)}$. Dessa maneira, pressupõe-se a participação ativa da pessoa no tratamento e não a passividade e obediência (compliance) frente às recomendações ${ }^{(5)}$.

$\mathrm{Na}$ perspectiva comportamental, o conceito de adesão está relacionado ao processo de enfrentamento e aprendizado que o usuário e os profissionais de saúde vivenciam. Portanto, aderir ao tratamento não se limita apenas ao cumprimento das recomendações, mas à possibilidade de construir ou fortalecer repertórios comportamentais(6).

O fenômeno da adesão ao tratamento pode ser focado no usuário ou nos fatores externos a ele(7), como, por exemplo, o papel da família, seja ela a incentivadora da participação do membro dependente no tratamento, ou ela participando deste(8). Quanto maior a participação de membros da família no processo terapêutico, melhor será a adesão do usuário e da família à terapia(4,9-10). O engajamento de um familiar à terapêutica pode ser facilitado quando ele estiver motivado para ajudar seu membro dependente químico(11).

Revisão integrativa que analisa a produção científica nacional sobre o papel da família no cuidado de seu parente consumidor de substâncias psicoativas aponta dificuldades de inserção desta no tratamento, justificadas pelos conflitos familiares, sobrecarga física e emocional e falta de intervenções ofertadas pelos serviços de saúde à família(4).

Entretanto, a maioria dos estudos tem dado maior ênfase à questão da adesão do usuário ao tratamento, do que à da família(12-13). Eles abordam fatores facilitadores para essa adesão ${ }^{(8,12)}$, que envolvem o tempo de permanência dele em tratamento(12), os processos motivacionais do usuário(8), a importância do vínculo(13) e aliança terapêutica entre usuário e profissional de saúde(13-14).

Percebe-se que, em relação ao processo terapêutico de dependentes químicos, poucos estudos abordam a adesão da família ao tratamento do seu membro dependente ${ }^{(15)}$.

Assim, tem-se como questão de pesquisa: Quais são os fatores auxiliares reconhecidos pela família para a sua adesão ao tratamento do seu membro familiar dependente químico?

Diante disso, este estudo justifica-se por sua relevância, pois subsidiará os profissionais de saúde na configuração de um cuidado ampliado ao membro familiar dependente em tratamento e à sua família, auxiliando-os no processo de inserção e permanência no tratamento.

O objetivo deste estudo consiste em analisar a percepção do membro familiar sobre as facilidades de adesão da família ao tratamento do dependente químico em acompanhamento no Centro de Atenção Psicossocial álcool e outras drogas.

\section{Método}

Pesquisa qualitativa, desenvolvida no período de novembro/2015 a outubro/2016 em um Centro de Atenção Psicossocial - álcool e drogas (CAPS ad) do interior paulista brasileiro, com seis famílias, sendo a amostra intencional de dez membros familiares de usuários de drogas. Os critérios de inclusão adotados foram: ser familiar com idade maior ou igual a 18 anos, independente do gênero, motivado ou não ao tratamento de seu membro adoecido, participante frequente e assíduo dos Grupos de Famílias por no mínimo três meses. Tal tempo foi baseado em evidências científicas que afirmam comportamento do dependente para adesão terapêutica após três meses de tratamento(12). Dessa maneira, acredita-se que a família pode permanecer o mesmo período, por reconhecer a adesão ao tratamento de seu ente dependente químico.

Os critérios de exclusão foram: membros familiares que estavam intoxicados por consumo de SPAs.

O recrutamento das famílias consistiu em indicação pelos profissionais de saúde do referido serviço, e das quinze famílias integrantes nos grupos, oito aceitaram participar da pesquisa. Entretanto, ao contatá-las via telefone, somente seis confirmaram participação.

As entrevistas semiestruturadas, realizadas em domicílio e no CAPS ad, foram gravadas por áudio, variando entre 45 minutos e 2 horas e meia de duração. Esse processo consistiu em caracterizar os participantes quanto aos dados de identificação pessoal, faixa etária, grau de parentesco com o dependente, configuração familiar e tempo de permanência no grupo de família. As questões norteadoras abordaram a importância da participação e permanência da família no tratamento e suas motivações.

Para o processo analítico dos dados, utilizou-se a técnica de análise de conteúdo temática ${ }^{(16)}$. Na primeira análise foram realizadas a leitura e a organização das entrevistas transcritas. Na fase seguinte, denominada de exploração, procedeu-se à leitura, linha por linha, do 
material coletado, o qual apontou frases que abordavam a participação da família no tratamento, os motivos da família em permanecer no tratamento, bem como o seu papel na terapia. Após a decomposição do conjunto das mensagens foram apreendidas e selecionadas as unidades de significado, por meio de recortes textuais da entrevista em temas ${ }^{(16)}$. Os temas foram agrupados por significados similares e diferentes e os relatos identificados em cada entrevista. Em seguida, fez-se agregação das falas ilustrativas das unidades de significado, codificação alfanumérica e nominação destas, com a finalidade de elaborar as primeiras categorias empíricas (momento de categorização)(16).

A etapa de tratamento dos resultados envolveu as fases de inferências e interpretações. Houve a descrição de cada categoria, com a produção de texto-síntese, expressando os significados temáticos. O processo de interpretação consistiu na agregação das informações obtidas, desvendando o conteúdo manifesto ou subjacente(16), com base na fundamentação dos conceitos de adesão, bem como na literatura sobre a temática.

As falas foram identificadas pela inicial "F"(Família), seguida pelas iniciais de parentesco ("M"-Mãe, "P"-Pai, "Io"-Irmão e "Ia"- Irmã, "V"-Avó e "E"-Esposa) e sequenciadas pelos números correspondentes à ordem das entrevistas realizadas.

O estudo respeitou os aspectos éticos da Resolução n. 466/2012 do Conselho Nacional de Saúde e foi aprovado pelo Comitê de Ética em Pesquisa em Seres Humanos, conforme parecer $n^{\circ}$. 1.114.587 de 14/07/2015.

\section{Resultados}

Na Figura 1, as famílias foram caracterizadas quanto ao grau de parentesco com o dependente, idade, tempo de acompanhamento no Grupo e idade do familiar entrevistado.

\begin{tabular}{|c|c|c|c|}
\hline $\begin{array}{l}\text { Família/ } \\
\text { Dados }\end{array}$ & $\begin{array}{c}\text { Membro familiar } \\
\text { participante e idade }\end{array}$ & $\begin{array}{c}\text { Tempo de } \\
\text { participação } \\
\text { no grupo }\end{array}$ & $\begin{array}{c}\text { Membro } \\
\text { dependente e } \\
\text { idade }\end{array}$ \\
\hline $\begin{array}{l}\text { Família } 1 \\
\text { (F1) }\end{array}$ & Mãe (M1) - 61 anos & 6 anos & $\begin{array}{c}\text { Filho }(U 1)-32 \\
\text { anos }\end{array}$ \\
\hline $\begin{array}{l}\text { Família } 2 \\
\text { (F2) }\end{array}$ & $\begin{array}{l}\text { Mãe (M2) - } 51 \text { anos } \\
\text { Pai (P2) - } 52 \text { anos } \\
\text { Irmã (la2) }-24 \text { anos } \\
\text { Irmão (lo2)- } 22 \text { anos }\end{array}$ & 5 meses & $\begin{array}{l}\text { Filha }(\mathrm{U} 2)-17 \\
\text { anos }\end{array}$ \\
\hline $\begin{array}{l}\text { Família } 3 \\
\text { (F3) }\end{array}$ & Mãe (M3) - 53 anos & 5 anos & $\begin{array}{c}\text { Filho (U3) - } 31 \\
\text { anos }\end{array}$ \\
\hline $\begin{array}{l}\text { Família } 4 \\
\text { (F4) }\end{array}$ & Avó (V4) - 71 anos & 6 anos & $\begin{array}{l}\text { Filha }(\mathrm{Ua} 4)-32 \\
\text { anos } \\
\begin{array}{l}\text { Neto }(\mathrm{Uo} 4)-15 \\
\text { anos }\end{array}\end{array}$ \\
\hline $\begin{array}{l}\text { Família } 5 \\
\text { (F5) }\end{array}$ & $\begin{array}{c}\text { Esposa }(E 5)-59 \\
\text { anos }\end{array}$ & 2 anos & $\begin{array}{c}\text { Esposo (U5) - } 53 \\
\text { anos }\end{array}$ \\
\hline $\begin{array}{l}\text { Família } 6 \\
\text { (F6) }\end{array}$ & $\begin{array}{l}\text { Mãe (M6) - } 56 \text { anos } \\
\text { Pai (P6) - } 61 \text { anos }\end{array}$ & 1 ano & $\begin{array}{l}\text { Filho }(\mathrm{U} 6)-40 \\
\text { anos }\end{array}$ \\
\hline
\end{tabular}

Figura 1 - Caracterização de dez membros familiares. São Paulo, Brasil, 2016
Na Figura 1, os membros familiares foram caracterizados quanto ao grau de parentesco com o dependente e idade, tempo de acompanhamento no Grupo e idade do familiar entrevistado.

Quanto à caracterização das famílias, três delas tinham configuração nuclear (pai, mãe e filhos), uma monoparental (mãe e filhos), outra reconstruída (filhos, mãe e um novo companheiro, sem ser o pai biológico) e uma família dança a dois (avó e neto, com a presença esporádica da mãe). A faixa etária dos membros variou de 22 a 71 anos, com média de 51 anos. Dos entrevistados, quatro eram mulheres, com papéis de mães, avó, esposa e irmã dos dependentes. Na entrevista, apenas em duas famílias houve participação dos homens na condição de pais ou irmãos dos usuários.

Foram criadas três categorias: Criação da aliança terapêutica, Expectativas positivas da família em relação à recuperação do usuário e Percepção da importância do papel familiar na continuidade do tratamento.

\section{Criação da aliança terapêutica}

Os grupos de família e a relação entre trabalhador de saúde do CAPS ad e familiares consistiram em alianças terapêuticas que favoreceram a adesão do familiar ao tratamento.

O grupo de família fortaleceu e promoveu aprendizado por possibilitar troca de experiências e reflexão entre as famílias.

Uma ajuda muito grande [do grupo de família] [...] nos fortalece, muito mesmo. Que a gente vê histórias, cada uma diferente [...] aquilo [grupo de família] dá uma força tão grande para a gente fortalecer, para sobreviver e saber lutar, que eu não tenho uma explicação. (F1M1)

A troca de experiências representou um momento em que as famílias se sentiram acolhidas. O grupo ofereceu consolo e amparo aos participantes, os quais perceberam que não estavam sozinhos na luta contra o consumo de substâncias psicoativas por seu familiar.

A gente [família] não se sente sozinho, a gente tem as experiências de outras pessoas, como a gente é experiência para outras pessoas. Então, essa colocação que a gente não está sozinha, que realmente o grupo de família tem ajudado a gente. (F2P2)

O aprendizado permitiu refletir sobre os modos de agir frente às situações críticas e realizar autoavaliação sobre o comportamento e as condutas tomadas. Anteriormente, os participantes sentiam-se perdidos em relação às suas ações, sem saberem como lidar com a situação e o parente.

Quando eu cheguei aqui [CAPS ad] eu era inexperiente, eu não tinha passado por essas coisas da vida, eu não sabia aonde pisar, aonde correr, a quem recorrer ou nem o que fazer. 
Tentando ajudar e sem saber. Hoje não, hoje, aos poucos, eu vou aprendendo tudo, aonde pisar, aonde eu vou, como fazer, com quem falar, com quem agir, de cabeça erguida. Então, foi um aprendizado muito grande. (F1M1)

O grupo constituiu fonte contínua de conhecimento sobre sintomatologia, sinais de abstinência e comportamento do usuário, o que motivou e incentivou a família a permanecer no tratamento.

Eu aprendi a lidar com a situação, conhecer quando vai [usuário] recair ou não. (F3M3)

Os grupos possibilitaram refletir sobre os casos expostos, comparar as experiências dos outros à própria realidade e exercitar empatia.

[O grupo de família] Ajuda-me a enxergar coisas que eu não estava enxergando [...] vivenciar os problemas das outras pessoas, me por no lugar delas, ver o que estava errado, o que eu estou fazendo de errado, tentar consertar. (F2M2)

A relação entre o profissional de saúde e os familiares foi focada no apoio informacional e na escuta qualificada.

Mas que me ajuda qualquer dúvida que eu tenho, qualquer coisa eu posso falar, não é? Do meu probleminha e o [nome do profissional de saúde], no caso vai me ajudar a como solucionar e ouvir também, lógico, que eu não sou perfeita. Se eu estou errada, se eu estou certa, não é? Em alguma atitude que eu tomo com ele [parente adoecido]. Então, por isso que eu quero continuar aqui [grupo de família]. (F4V1)

\section{Expectativas positivas da família em relação à recuperação} do usuário

A expectativa positiva da família de que o membro volte a ser a mesma pessoa que era antes da dependência química e retorne às rotinas e hábitos de vida anteriores favorece a adesão dos familiares ao tratamento. Tais fatos dependem do apoio Divino e da conquista de trabalho formal.

[...] então, um dia, Deus [...] [nome do usuário] vai voltar a ser o que era [...]. (F1M1); Se ele [usuário] conseguir um emprego, trabalhar, tiver uma renda, eu acho que ele melhora [...] aí ele volta a ser aquela pessoa que ele era, entendeu? (F5E1)

Para os familiares, a recuperação é obtida na ausência de recaída.

Peço a Deus que ele [usuário] jamais tenha recaída. (F1M1)

A esperança da melhora do usuário depende da primeira internação em clínicas especializadas de dependência química, com perspectivas de convivência social, restabelecimento de vínculos familiares e busca pela felicidade.
Na primeira vez que você interna, a minha esperança era que aqui era a primeira vez que ela [usuária] ia realmente entrar numa clínica especializada para dependentes químicos, não é? Com profissionais e tal; então, eu achei, assim, aquela esperança de que ela ia sair dali boa. (F5V1); Esperança de ver a outra pessoa bem e a vontade de sair desse problema, de voltar a ter uma vida normal, de se encaixar ao que é considerado os padrões da sociedade e viver bem. Voltar a ser feliz, ter um vínculo familiar bom $[\ldots]$. (F2Io2)

Percepção da importância do papel familiar na continuidade do tratamento.

A família reconheceu seu papel singular na recuperação do membro em tratamento e adesão terapêutica, ao ofertar suporte ao usuário. O lutar e não desistir do familiar a ajudou a ser persistente no continuum do tratamento.

E vou continuar lutando [...] E não desisto. Que não adianta, eu já falei para eles [outros filhos]: não adianta, seu irmão precisa de ajuda e enquanto a mãe estiver [viva], a mãe não vai deixar ele sozinho. (F1M1)

O apoio familiar também foi compreendido na forma de não abandonar o familiar adoecido, mas de aproximá-lo ao convívio da família e dialogar com ele, ao dar-lhe apoio emocional e criar ou resgatar rituais familiares salutares. Tal estratégia incentivou a permanência do membro dependente químico e da família no tratamento.

Eu acho que a gente tem que estar do lado da pessoa, não abandonar, porque você estando do lado já é difícil, se você abandonar é pior. [...] Conversar, ver se está tudo bem, não abandonar, convidar para vir passar o final de semana em casa, um almoço, uma janta que a gente está em casa [...] Porque ajuda que você pode dar, é emocional, não é financeira; então, é conversando, entender [...]. (F3M3)

Outra estratégia de suporte familiar consistiu em monitorar os momentos de intenso desejo do uso da droga (fissura) e acompanhar a rotina diária do ente dependente, para prevenir a recaída.

Conversar, sempre estou dando dica: 'Oh, cuidado, você está indo para um lado que é recaída; você vigia para ver se está recaindo'. [...] estou no controle assim, converso bastante com ele [familiar adoecido]; ligo de dia para ver se está bem, ligo de noite para ver se está bem [...] então eu aprendi nas atitudes do meu filho, quando ele está para ir para recaída. (F3M3)

A união familiar e o tratamento de seus membros podem demonstrar o comprometimento e envolvimento da família para a continuidade do tratamento.

Então, se a família não estiver junto, não faz sentido ela [usuária] ir para clínica. Não faz sentido nem iniciar algum tipo 
de tratamento. E a importância que a gente tem no tratamento, a gente também faz parte disso, não tem como pensar: 'a [nome da usuária] está se recuperando e a gente não faz parte disso?'. É uma coisa só, não faz sentido ela estar lá [no serviço de saúde] e a gente não se tratar daqui. Não tem como separar, não é? Não tem como falar o que a família vai fazer para melhorar ela. É todo mundo se tratando. (F2Ia2)

A obrigatoriedade no cuidado da família com seu membro adoecido foi relacionada ao seu modo interacional, de acordo com o compromisso matrimonial, patriarcal ou maternal. Em outros momentos, a falta de coragem do familiar em abandonar o ente, possibilitou recorrer a outros recursos para protegê-lo.

Eu já tive mil vezes vontade de separar, não queria mais, mas ele não tem para onde ir. Se eu separar, ele vai ficar na rua [...] Eu sei que se eu me separar, se eu não ajudar, aí [o esposo adoecido] vai para o fundo do poço, não vai ter jeito, então é isso que me motiva a ajudar e também não tem saída. (F5E1); Nós [pai e mãe do usuário] decidimos assim: 'nós temos dois caminhos a seguir - ou separava e punha ele no quarto dele [usuário] ou a gente põe ele para rua'. É como falei no grupo de família: 'Eu não tenho coragem de por um filho na rua'. [...] e separar o quarto, foi onde ele ajudou o pai dele a separar o quarto. [...] Ele é muito violento [...] se for violento na rua, vão matar ele. Por isso que eu não o ponho na rua, porque sei que ele não dura muito tempo. (F6M6).

\section{Discussão}

Na primeira categoria, os participantes do estudo reconheceram o grupo de família como espaço de fortalecimento, aprendizado e motivação para continuidade do tratamento das próprias famílias e de seus membros dependentes. Assim, criar aliança terapêutica entre os próprios familiares e entre familiares e a equipe do CAPS ad favorece a adesão.

Os dados corroboraram estudos sobre troca de experiências vividas por familiares em situações semelhantes em grupo, a qual os ajudou a sentirem-se acolhidos, pertencentes ao grupo, fortalecidos e motivados para auxiliarem outros membros familiares na adesão ao tratamento(13,17-18). Tais oportunidades em grupo terapêutico proporcionam a aquisição de novos laços de amizade(19) e esperança na recuperação do membro consumidor de substâncias psicoativas ${ }^{(13,18)}$.

Essa permuta de experiências, apesar das singularidades de cada família, promove reflexões, mútua ajuda e estimula a busca de sentidos únicos e diferentes nessa trajetória de cuidar-se e cuidar do outro. A sensação da família, participante deste estudo, em não se sentir sozinha na trajetória terapêutica, e poder compartilhar a sua experiência, possibilitou-lhe sentir-se aliviada e pertencente ao grupo. Além disso, ela reconheceu que seus problemas eram simples e fáceis de serem enfrentados diante daqueles expressos por outros membros, conforme estudos ${ }^{(3,13,17)}$.

Tais dados corroboraram a literatura ${ }^{(3,13,17)}$ ao sinalizar que o grupo de família é acolhimento, suporte e fonte de escuta(3,13,17,19), bem como proporciona amparo e conforto à família, facilitando seu envolvimento no tratamento(20).

O processo de compartilhar potencialidades, dificuldades e desafios entre as famílias desencadeia uma rede social e terapêutica, em que seus participantes interagem entre si, identificam-se, constroem e reconstroem suas vidas.

Os relatos dos familiares confirmaram estudos que apontam o grupo familiar como espaço de aprendizado, pois constitui fonte de informação e orientação(3,13,17) e possibilita mudança de comportamento familiar(3,19). Informações obtidas pelos participantes sobre a dependência química (sintomatologia e sinais de abstinência) e atitudes do usuário possibilitaram aprendizado e manejo de situações de recaída, corroborando a literatura(13,17,19). Entretanto, o serviço de saúde deve atentar para não tornar a família tão somente uma receptora de orientações, mas sim elaborar projetos terapêuticos direcionados a ela(4).

Os achados deste estudo ressaltaram que o grupo instrumentaliza e fortalece os familiares para a convivência diária e para o cuidado com seu ente dependente, conforme a literatura ${ }^{(3,13,18)}$. Assim, o grupo se constitui em fonte contínua de conhecimento que motiva e incentiva a família ao engajamento e permanência aderida no tratamento.

No espaço do grupo, as famílias podem refletir, autoavaliar-se, descobrir ou redescobrir habilidades que as ajudam a enfrentar e solucionar os problemas no cotidiano de suas vidas, tendo como subsídio o compartilhamento das histórias de seus membros.

Determinado estudo com familiares de crianças e adolescentes com sofrimento mental que participam de grupo operativo aponta que este Ihes possibilita a reflexão e internalização de saberes para resolução de problemas $^{(20)}$.

O grupo possibilita o processo de autorreflexão e autoconhecimento(20), potencializando os membros familiares para identificarem-se com situações advindas das vivências alheias. Entretanto, tais experiências geram ressonâncias no coletivo e oportunizam revisão de saberes, crenças, sentimentos, emoções, atitudes e comportamentos dos familiares.

Os relatos corroboraram estudo que ressalta que a aliança terapêutica entre equipe de saúde e usuários e/ou familiares está associada à melhor adesão ao tratamento(21). Estudo investigativo dos motivos para o engajamento terapêutico de jovens e famílias que vivenciam o primeiro episódio psicótico apontou a 
importância do relacionamento terapêutico com a equipe de saúde. O engajamento de ambos representa resultado do processo comunicacional e informacional dos profissionais ${ }^{(21)}$ sobre a dependência química, de seus apoios ofertados e de suas posturas otimistas em relação à recuperação dos usuários ${ }^{(21)}$.

Na segunda categoria, a adesão da família ao tratamento de seu membro dependente é impulsionada pelas suas expectativas positivas em relação à recuperação de seu parente.

Estudo com familiares de dependentes aponta que $83 \%$ deles têm expectativas de recuperação e cura para o seu membro familiar(22), corroborando os achados do presente estudo de que o usuário retornará aos antigos hábitos de vida, por intermédio de força Divina e labor.

De fato, há estudo que salienta a expectativa de usuários de drogas em retornarem a antigos hábitos de vida por meio do trabalho e estudo(23). O trabalho no processo de recuperação do dependente químico pode ter papel importante para reorganizar e restabelecer a rotina diária da pessoa, resgatar elevada autoestima, reconhecê-la como cidadã de direitos e reinseri-la socialmente. Porém, pode ser fonte geradora de estresse, agindo como fator de risco para a pessoa com dificuldades de competir nesse meio(24).

Compreende-se que o processo de recuperação requer tempo e investimentos da família, usuário, equipe de saúde e do governo. Tais investimentos perpassam dimensões culturais, sociais, econômicas, jurídicolegais, técnico-científicas e políticas. Há necessidade de políticas públicas de saúde e trabalhistas que possibilitem a inserção desse usuário em novo mercado de trabalho, rompendo assim o estigma e o preconceito da sociedade.

Em nossos achados, as famílias reforçaram a visão de que a recuperação se baseia na cura, abstinência das drogas e prevenção de recaída, corroborando estudo que relaciona tal percepção ao modelo biológico ou de doença(4).

Uma família participante deste estudo teve esperança de que a primeira internação em comunidades terapêuticas ou clínicas especializadas poderia curar seu parente, corroborando a literatura ${ }^{(4)}$. Provavelmente, por ser a primeira experiência de internação dessa família, essa crença e hipótese estão mais intensas. Efetivamente, a família acredita que a internação é primeira e única solução para a cura, tornando-se um recurso imediatista ${ }^{(4)}$. Porém, a atual política de saúde mental brasileira tem investido em acompanhamento terapêutico em serviços abertos de base comunitária, baseados na política estratégica de Redução de Danos ${ }^{(4)}$. Essa política propõe ações de cuidado que permitem ao sujeito relacionar-se com a substância de maneira menos prejudicial à sua saúde, sem necessariamente reduzir ou cessar o consumo. Todavia, a esperança promove forças motivadoras à família para persistir no tratamento de seu parente ${ }^{(25)}$.

Os achados da última categoria confirmaram estudos os quais apontam que as famílias têm papel de apoiadores no tratamento(21-22), não desistindo de ajudar seu familiar dependente ${ }^{(4)}$. Luta e persistência perpassaram a trajetória dessas famílias, auxiliando-as na adesão terapêutica.

Apesar das dificuldades enfrentadas pelas famílias participantes deste estudo, elas se mobilizaram para apoiar emocionalmente seu parente, aproximando-o do convívio familiar e resgatando rituais e rotinas familiares diárias saudáveis. O contexto familiar pode se configurar enquanto fator de proteção na vida do usuário(26). Outro estudo sobre forças facilitadoras em famílias com membro portador de transtorno mental ressalta a importância de incluir práticas prazerosas diárias junto aos seus membros; além de incentivar e encorajar o familiar no processo de comunicação assertiva e adesão às rotinas ${ }^{(27)}$.

Para os entrevistados, outro papel importante da família consistiu em monitorar o comportamento do dependente químico em relação à recaída. Esta consiste em um dos fatores que mais afligem as famílias de dependentes de drogas ${ }^{(27)}$. Apesar da importância desse ato, necessita-se de atenção ao processo de envolvimento emocional intenso pelos membros familiares, denominado de codependência. No processo de cuidar, há uma preocupação e dedicação obsessiva do membro familiar com o dependente químico, na tendência de controlar o seu comportamento, esquecendo-se de cuidar de si mesmo(2).

Entretanto, os achados deste estudo salientaram que a união da família demonstrou compromisso no tratamento. Todos somam forças para que o objetivo final seja alcançado com sucesso, ou seja, a recuperação do membro e da família, reestruturação e melhor convivência familiar. Porém, para que isso ocorra, todos devem participar do processo terapêutico. Dessa forma, a adesão da família( ${ }^{(3-4)}$ e de seu familiar(4) no tratamento envolve grau de envolvimento e participação de ambos no cuidado.

Tal grau de envolvimento familiar pode relacionar-se ao sentimento de obrigatoriedade em cuidar do seu ente em tratamento, conforme achado deste estudo. A literatura aponta que tal sentimento representa uma necessidade intrínseca à condição humana, em que o indivíduo se compromete a cuidar do outro como ideal ético, englobando atos, comportamentos e atitudes, com fins de promover o bem-estar e a recuperação do ser cuidado(28). Entretanto, a codependência pode desencadear sentimentos de culpa no familiar e/ou dependência emocional entre familiar e usuário de drogas $^{(2)}$, exigindoIhe dedicação constante no cuidado. O familiar pode sentir-se ética e moralmente responsável pelo cuidado de seu parente, pelo receio de ser julgado negativamente pela sociedade. 


\section{Conclusão}

O presente estudo concluiu que as famílias reconheceram que criar alianças terapêuticas, ter esperança na recuperação do seu parente e valorizar seus papeis participativos no tratamento familiar facilitam a sua adesão terapêutica.

As limitações deste estudo relacionam-se à participação somente de duas famílias que continham mais que um membro na entrevista, o que proporciona uma visão mais do coletivo familiar e não a visão individual. Entretanto, os resultados desta pesquisa contribuem para a reflexão dos profissionais de saúde quanto às possíveis áreas estratégicas no cuidado com as famílias, de modo a ajudá-las na adesão terapêutica.

\section{Referências}

1.Bortolon CB, Signor L, Moreira TC, Figueiró LR, Benchaya MC, Machado CA et al. Family functioning and health issues associated with codependency in families of drug users. Ciênc Saúde Coletiva. [Internet]. 2016;21(1):10017. [cited Oct 28, 2018]. Available from: http://www.scielo. br/pdf/csc/v21n1/1413-8123-csc-21-01-0101.pdf.

2.Costa B, Marcon SS, Paiano M, Sales CA, Maftum MA, Waidman MAP. Feelings and codependent behavior in the family of illicit drugs users. Acta Sci Anim Sci. [Internet]. 2017;39(2):175-81. [cited Oct 28, 2018]. Available from: http://www.redalyc.org/articulo.oa?id=307252895007

3.Nascimento LTR, Souza J, Gaino LV. Relationship between drug dependence and alcohol users receiving treatment in a community health center specializing in alcohol treatment. Texto Contexto Enferm. 2015;24(3):834-41. doi: http:// dx.doi.org/10.1590/0104-07072015003610013.

4.Belotti M, Fraga HL, Belotti L. Família e atenção psicossocial: o cuidado à pessoa que faz uso abusivo de álcool e outras drogas. Cad Bras Ter Ocup. 2017;25(3):617-25. doi: http://dx.doi.org/10.4322/25268910.ctoAR0988.

5. Chakrabarti S. What's in a name? Compliance, adherence and concordance in chronic psychiatric disorders. WId J Psychiatry.[Internet]. 2014;4(2):30-6. [cited Oct 28, 2018]. Available from: https://www.ncbi. nlm.nih.gov/pmc/articles/PMC4087153/pdf/WJP-4-30.pdf. 6. Moraes ABA, Rolim GS, Costa AL Jr. O processo de adesão numa perspectiva analítico comportamental. Rev Bras Ter Comport Cogn. [Internet]. 2009;11(2):32945. [Acesso 4 jan 2018]. Disponível em: http://pepsic. bvsalud.org/scielo.php?script=sci_arttext\&pid=S151755452009000200009\&Ing=pt .

7.Leite SN, Vasconcellos MPC. Adesão à terapêutica medicamentosa: elementos para a discussão de conceitos e pressupostos adotados na literatura. Ciênc Saúde Coletiva. [Internet]. 2003;8(3):775-82. doi: http://dx.doi. org/10.1590/S1413-81232003000300011.
8.Scaduto AA, Barbieri V. O discurso sobre a adesão de adolescentes ao tratamento da dependência química em uma instituição de saúde pública. Ciênc Saúde Coletiva. [Internet]. 2009;14(2):605-14. doi: http://dx.doi. org/10.1590/S1413-81232009000200029 .

9. Alvarez SQ, Gomes GC, Oliveira AMN, Xavier DM. Grupo de apoio/suporte como estratégia de cuidado: importância para familiares de usuários de drogas. Rev Gaúch Enferm. [Internet]. 2012;33(2):102-8. doi: http:// dx.doi.org/10.1590/S1983-14472012000200015 .

10.Paz AZ FM, Colossi PM. Aspectos da dinâmica da família com dependência química. Estud Psicol. [Internet]. 2013;18(4):551-8. [Acesso 2 jan 2016]. Disponível em: http://www.scielo.br/pdf/epsic/v18n4/a02v18n4.pdf . 11. Maciel LD, Zerbetto SR, Filizola CLA, Dupas G, Ferreira NMLA. Consequências e dificuldades da dependência química no âmbito familiar: uma revisão de literatura. Rev APS. [Internet]. 2013;16(2):187-96. [Acesso 28 out 2018]. Disponível em: https://aps.ufjf.emnuvens.com.br/ aps/article/view/1809/721.

12. Monteiro CFS, Fé LCM, Moreira MAC, Albuquerque IEM, Silva MG, Passamani MC. Perfil sociodemográfico e adesão ao tratamento de dependentes de álcool em CAPS-ad do Piauí. Esc Anna Nery. 2011; 15(1):90-5. doi: http://dx.doi.org/10.1590/S1414-81452011000100013 . 13.Vasters GP, Pillon SC. Drugs use by adolescents and their perceptions about specialized treatment adherence and dropout. Rev. Latino-Am. Enfermagem. 2011; 19(2): 317-24. doi: http://dx.doi.org/10.1590/S010411692011000200013 .

14. Ribeiro DVA, Turato ER, Azevedo RCS, Campos CJG. Views on treatment adherence among psychoactive substance-dependent women in the outpatient setting: a qualitative study. Trends Psychiatry Psychother. 2012;34(4):192-206. doi: http://dx.doi.org/10.1590/ S2237-60892012000400005

15.Seleghim MR, Oliveira MLF. Influence of the family environment on individuals Who use crack. Acta Paul Enferm. [Internet]. 2013;26(3):263-8. doi: http://dx.doi. org/10.1590/S0103-21002013000300010

16. Minayo MCS. O desafio do conhecimento: pesquisa qualitativa em saúde. 14th ed. São Paulo: Hucitec; 2014. 17.Gomes RJ, Martos CC, Cavalari MCA, Rossetto AA. Atendimento grupal: trabalhando a codependência. Colloquium Humanarum. [Internet]. 2012; 9(n.esp): 508-16. [Acesso 2 jan 2016]. Disponível em: http:// www.unoeste.br/site/enepe/2012/suplementos/area/ Humanarum/Ci\%C3\%AAncias\%2OHumanas/Psicologia/ ATENDIMENTO $\% 20$ GRUPAL $\% 20$ TRABALHANDO $\% 20$ A $\% 20$ CO-DEPEND\%C3\%8ANCIA.pdf

18. Alves RD, Morais TTM, Rocha SP, Rocha NNV, Duarte SR, Sampaio FFF. Grupos de familiares em CAPS ad: acolhendo e reduzindo tensões. Sanare, Rev Políticas Públicas. [Internet]. 2015; 14(1):81-6. [Acesso 2 jan 
2016]. Disponível em: https://sanare.emnuvens.com. br/sanare/article/view/613/330

19.Duarte MLC, Viana KR, Olschowsky A. Crack users' evaluation regarding family groups in the psychosocial care center. Cogitare Enferm. [Internet]. 2015;20(1): 81-8. [Acesso 4 jan 2018]. Disponível em: http://dx.doi. org/10.5380/ce.v20i1.37597

20.Albuquerque MCS, Nascimento YCML, Brêda MZ, Luca LCG. Mudanças percebidas por familiares de crianças/ adolescentes em sofrimento mental que participam de grupos operativos. Rev Eletr Enferm. 2014;16(3):652-61. doi: https://doi.org/10.5216/ree.v16i3.21777

21.Stewart KD. Factors contributing to engagement during the initial stages of treatment for psychosis. Qual Health Res. 2012;23(3):336-47. doi: http://journals.sagepub. com/doi/10.1177/1049732312468337.

22.Xavier MF, Rodrigues PHJ, Silva MCR. A percepção da família no tratamento e suporte de dependentes químicos. Encontro, Rev Psicol. [Internet]. 2014;17(26):99110. [Acesso 4 jan 2016]. Disponível em: http:// www.pgsskroton.com.br/seer/index.php/renc/article/ view/2419/2319.

23.Gomes RR, Ribeiro MC, Matias EC, Brêda MZ, Mângia EF. Motivation and expectations in treatment search for abusive use and addiction of crack, alcohol and other drugs. Rev Ter Ocup Univ São Paulo. 2015;26(3):32635. doi: http://dx.doi.org/10.11606/issn.2238-6149. v26i3p326-335.

24.Silva AC, Weber F, Adan A, Hidalgo MPL. O papel do trabalho no processo saúde-doença em dependentes de crack. Arq Ciênc Saúde. 2015;22(1):48-52. doi: https:// doi.org/10.17696/2318-3691.22.1.2015.26

25.Zauszniewski JA, Bekhet AB, Suresky MJ. Indicators of resilience in family members of adults with serious mental illness. Psychiatr Clin North Am. 2015;38(1):131-46. doi: http://dx.doi.org/10.1016/j.psc.2014.11.009

26. Marcon SR, Sene JO, Oliveira JRT. Contexto familiar e uso de drogas entre adolescentes em tratamento. SMAD, Rev Eletrônica Saúde Mental Álcool Drog. [Internet]. 2015;11(3):122-8. [Acesso 20 ago 2018]. Disponível em: http://pepsic.bvsalud.org/pdf/smad/v11n3/pt_02.pdf 27. Bishop M, Greeff AP. Resilience in families in which a member has been diagnosed with schizophrenia. J Psychiatr Ment Health Nurs. [Internet]. 2015;22(7):46371. [cited Jan 4 2018]. Available from: http://onlinelibrary. wiley.com/doi/10.1111/jpm.12230/epdf

28. Waldow VR, Borges RF. Caring and humanization: relationships and meanings. Acta Paul Enferm. [Internet].
2011;24(3):414-8. doi: http://dx.doi.org/10.1590/ S0103-21002011000300017.

\section{Contribuição dos Autores}

Concepção e planejamento do estudo: Ana Carolina Belmonte Assalin, Sonia Regina Zerbetto. Obtenção dos dados: Ana Carolina Belmonte Assalin, Sonia Regina Zerbetto, Bianca Oliveira Ruiz. Análise e interpretação dos dados: Ana Carolina Belmonte Assalin, Sonia Regina Zerbetto. Redação do manuscrito: Ana Carolina Belmonte Assalin, Sonia Regina Zerbetto. Revisão crítica do manuscrito: Ana Carolina Belmonte Assalin, Sonia Regina Zerbetto, Bianca Oliveira Ruiz, Priscila Souza, Sarah Salvador Pereira.

Todos os autores aprovaram a versão final do texto. Conflito de interesse: os autores declararam que não há conflito de interesse.
Copyright $\odot 2021$ SMAD, Rev. Eletrônica Saúde Mental Álcool Drog. Este é um artigo de acesso aberto distribuído sob os termos da Licença Creative Commons CC BY-NC.

Esta licença permite que outros remixem, adaptem e criem a partir do seu trabalho para fins não comerciais, e embora os novos trabalhos tenham de lhe atribuir o devido crédito e não possam ser usados para fins comerciais, os usuários não têm de licenciar esses trabalhos derivados sob os mesmos termos. 